\title{
Dexmedetomidine is effective for monitored anesthesia care in outpatients undergoing cataract surgery
}

\author{
Hyo-Seok Na ${ }^{1}$, In-Ae Song ${ }^{1}$, Hong-Sik Park ${ }^{2}$, Jung-Won Hwang ${ }^{1}$, Sang-Hwan Do $^{1}$, and Chong-Soo Kim ${ }^{3}$ \\ Department of Anesthesiology and Pain Medicine, ${ }^{1}$ Seoul National University Bundang Hospital, Seongnam, ${ }^{2}$ Seoul National \\ University Hospital, ${ }^{3}$ Boramae Medical Center, Seoul, Korea
}

Background: Dexmedetomidine has a sedative analgesic property without respiratory depression. This study evaluated the efficacy of dexmedetomidine as an appropriate sedative drug for monitored anesthesia care (MAC) in outpatients undergoing cataract surgery on both eyes compared with combination of propofol and alfentanil.

Methods: Thirty-one eligible patients were randomly divided into two groups on the first operation day. Dexmedetomidine was administered in group D at $0.6 \mu \mathrm{g} / \mathrm{kg} / \mathrm{h}$, and propofol and alfentanil was infused concomitantly in group P at a rate of $2 \mathrm{mg} / \mathrm{kg} / \mathrm{h}$ and $20 \mu \mathrm{g} / \mathrm{kg} / \mathrm{h}$, respectively. Sedation was titrated at Ramsay sedation score 3. Iowa satisfaction with anesthesia scale (ISAS) of the patients was evaluated postoperatively. Systolic blood pressure (SBP), heart rate (HR), respiration rate (RR), and peripheral oxygen saturation $\left(\mathrm{SpO}_{2}\right)$ were recorded throughout the surgery. For the second operation, the group assignments were exchanged.

Results: Postoperative ISAS was 50.3 (6.2) in group D and 42.7 (8.7) in group P, which was statistically significant (P< 0.001). SBP was significantly lower in group D compared with group $P$ from the beginning of the operation. HR, RR, and $\mathrm{SpO}_{2}$ were comparable between the two groups. There were 8 cases (25.8\%) of hypertension in group $\mathrm{P}$, and 1 case $(3.2 \%)$ in group $\mathrm{D}(\mathrm{P}<0.05)$. In contrast, 1 case $(3.2 \%)$ of hypotension and 1 case $(3.2 \%)$ of bradycardia occurred in group D.

Conclusions: Compared with the combined use of propofol and alfentanil, dexmedetomidine could be used appropriately for MAC in cataract surgery with better satisfaction from the patients and a more stable cardiovascular state. (Korean J Anesthesiol 2011; 61: 453-459)

Key Words: Cataract, Dexmedetomidine, Monitored anesthesia care, Propofol.

Received: April 25, 2011. Revised: May 9, 2011. Accepted: May 13, 2011.

Corresponding author: Chong-Soo Kim, M.D., Department of Anesthesiology and Pain Medicine, Boramae Medical Center, 41, Boramae-gil, Dongjak-gu, Seoul 156-707, Korea. Tel: 82-2-870-2511, Fax: 82-2-870-3863, E-mail: cskim@brm.co.kr

(c) This is an open-access article distributed under the terms of the Creative Commons Attribution Non-Commercial License (http:// creativecommons.org/licenses/by-nc/3.0/), which permits unrestricted non-commercial use, distribution, and reproduction in any medium, provided the original work is properly cited. 


\section{Introduction}

Cataract surgery can be performed safely under monitored anesthesia care (MAC) with or without local anesthesia [1]. Several drugs, such as propofol, benzodiazepine, and opioids have been used for MAC either alone or in combination [2-4].

Benzodiazepine may cause excessive sedation and confusion especially in elderly patients [5], and propofol can also result in disorientation and excessive sedation [6]. Because these drugs have no analgesic component, overdose with a rescue opioid is often given to prevent the unintentional reflex to painful stimuli, and thus may result in a higher incidence of confusion, excessive sedation, or disorientation. Additionally, respiration is depressed more often when additional opioids are used.

Considering that most of the patients undergoing cataract surgery are elderly, the above-mentioned aspects can be serious potential problems. Based on the analysis of the American Society of Anesthesiologists Closed Claims database, overdose of sedative or opioid leading to respiratory depression was the most common (24\%) in MAC claims, and $40 \%$ of these resulted in permanent brain damage or death [7].

Dexmedetomidine is a novel selective $\alpha_{2}$ receptor agonist that produces sedation and analgesia without causing respiratory depression [8]. It also allows patients to respond to verbal commands during the sedation; easy conversion from sleeping to awakening is possible [9]. Therefore, dexmedetomidine has been used in various clinical fields, such as sedation in the intensive care unit, radiologic examination of pediatric patients, awake intubation, shockwave lithotripsy, endoscopic examination [10-14] and as an adjuvant to anesthetics $[15,16]$.

Accordingly, we evaluated the efficacy of dexmedetomidine as an appropriate sedative drug for MAC in outpatients undergoing cataract surgery, which included a survey of the patients' satisfaction.

\section{Materials and Methods}

This study was approved by the Institutional Review Board and all participants gave written informed consent for this study. This trial was conducted in adult outpatients aged between 20 and 75 years. They were American Society of Anesthesiologists (ASA) classification I, II, or III and scheduled for sequential cataract surgery on both eyes under MAC. Preoperative exclusion criteria were pregnancy, kidney or hepatic disease, chronic medication with analgesic or sedative drug, or history of alcohol or drug abuse.

On the first operation day, patients were randomized to receive either dexmedetomidine (group $\mathrm{D}$ ) or combination of propofol and alfentanil (group P). Patients fasted at least 8 hours before the operation and did not receive any preoperative sedative drug. On arriving at the operating room, standard monitoring, including electrocardiography, non-invasive arterial pressure, and peripheral pulse oximetry was applied. Oxygen was administered via nasal cannula at $5 \mathrm{~L} / \mathrm{min}$. Topical anesthesia using sterile $0.5 \%$ proparacaine $\mathrm{HCl}$ ophthalmic solution was applied to the eye of patients.

Patients of group D received $0.6 \mu \mathrm{g} / \mathrm{kg} / \mathrm{h}$ of dexmedetomidine, and patients of group P were given $2 \mathrm{mg} / \mathrm{kg} / \mathrm{h}$ of propofol and $20 \mu \mathrm{g} / \mathrm{kg} / \mathrm{h}$ of alfentanil concomitantly. Dexmedetomidine was diluted in $2 \mu \mathrm{g} / \mathrm{ml}$ in normal saline for group $\mathrm{D}$, and $100 \mathrm{mg}$ of propofol and 1,000 $\mu \mathrm{g}$ of alfentanil were mixed to become total $12 \mathrm{ml}$ volume for group P. Each drug was titrated every $5 \mathrm{~min}$ to Ramsay sedation scale 3 during the operation (Appendix 1) [17]. Administration of dexmedetomidine was adjusted by $0.1 \mu \mathrm{g} /$ $\mathrm{kg} / \mathrm{h}$, and mixture of propofol and alfentanil were adjusted by $0.3 \mathrm{mg} / \mathrm{kg} / \mathrm{h}$ and $3 \mu \mathrm{g} / \mathrm{kg} / \mathrm{h}$, respectively. Ephedrine $5 \mathrm{mg}$ was administered when systolic blood pressure (SBP) decreased below $90 \mathrm{mmHg}$ or $70 \%$ of the preoperative value, and nicardipine $1 \mathrm{mg}$ was given when SBP went over $160 \mathrm{mmHg}$ or $130 \%$ of the preoperative value. Atropine $0.5 \mathrm{mg}$ was injected to the patients when heart rate (HR) fell below 40 beats/min.

The infusion was stopped at the end of the surgery in both groups. In the recovery center for outpatients, patients were asked to answer the 11 questions of Iowa satisfaction with anesthesia scale (ISAS) using a 6 point rating scale (Appendix 2) [18] at least 1 hour after the operation. It was performed by one anesthesiologist who was blinded to the group assignment.

SBP, HR, respiratory rate (RR), and peripheral oxygen saturation $\left(\mathrm{SpO}_{2}\right)$ were recorded at each time point as follows; $\mathrm{T} 1$ = preoperative baseline, $\mathrm{T} 2=$ anesthesia start, $\mathrm{T} 3$ and $\mathrm{T} 4$ = 5 and $10 \mathrm{~min}$ after anesthesia, T5 = operation start, T6, T7, and $\mathrm{T} 8=5,10$, and $15 \mathrm{~min}$ after operation, $\mathrm{T} 9=$ postoperative value. Moreover, the incidence of adverse events including hypertension (SBP $>160 \mathrm{mmHg}$ ), hypotension (SBP $<90 \mathrm{mmHg}$ ), bradycardia ( $\mathrm{HR}<50$ beats/min), respiratory depression $(\mathrm{RR}<$ 10 breaths $/ \mathrm{min})$, and oxygen desaturation $\left(\mathrm{SpO}_{2}<93 \%\right)$ were evaluated.

The second operation was performed one or two weeks later. On the second operation day, patients previously in one group were assigned to the opposite group. Except for the exchange of infused drugs, all other methods were identical to the first trial.

The primary effect variable, used for power calculation analysis, was the difference of ISAS. With an assumption of a difference in means of 5.0 and a SD of 6.8 (data not shown), and aiming at a power of $80 \%$ and a risk of 0.05 for type I error, 31 patients in each group were required. Data were presented as mean \pm SD. ISAS was compared using Mann-Whitney U test. Hemodynamic and respiratory data were analyzed using repeated measures ANOVA, and when a significant inter-group difference was found, the Mann-Whitney U test was used at 


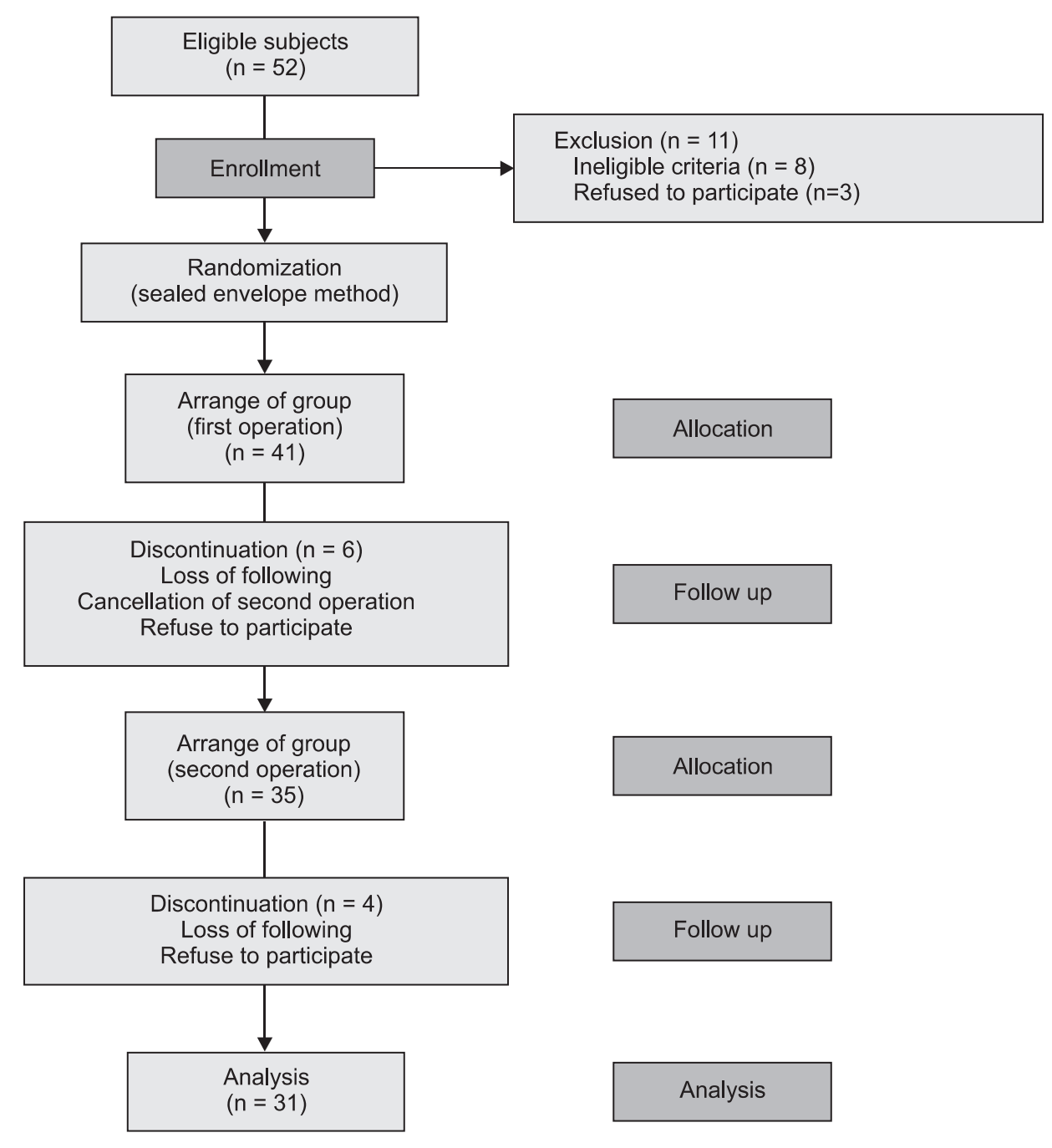

Fig. 1. Enrollment of patients.

each time points. The Fisher's exact test was used to determine the incidence of adverse events. Statistical analyses were performed using SPSS 15.0 version (SPSS Inc, Chicago, IL) and $P$ values of $<0.05$ were considered statistically significant.

\section{Results}

A total of 52 patients were recruited, and 11 patients of these were excluded from this study. After initiation of the study, 10 patients dropped out of the study (Fig. 1). Finally, 16 patients were arranged in order, beginning with group $\mathrm{P}$ at the first operation and then group D at the second operation. The other 15 patients were assigned first to group D and next to group P. The characters of subdivided groups at first operation are presented in Table 1, and no significant differences were seen between the groups. Total anesthesia time was $36.0 \pm 6.1 \mathrm{~min}$ in group $\mathrm{D}$ and $38.2 \pm 7.3 \mathrm{~min}$ in group $\mathrm{P}$, and operation time was $21.0 \pm 5.6 \mathrm{~min}$ and $20.7 \pm 5.1 \mathrm{~min}$ in group $\mathrm{D}$ and $\mathrm{P}$, respectively.
Table 1. Patients' Characteristics at the First Operation

\begin{tabular}{lcc}
\hline & Group P $(\mathrm{n}=16)$ & Group D $(\mathrm{n}=15)$ \\
\hline Age & $57.4 \pm 13.4$ & $60.8 \pm 11.4$ \\
Height & $162.4 \pm 6.5$ & $160.8 \pm 8.7$ \\
Weight & $67.8 \pm 10.3$ & $64.0 \pm 12.7$ \\
Gender (M/F) & $8 / 8$ & $5 / 10$ \\
ASA (I/II/III) & $5 / 7 / 4$ & $4 / 8 / 3$
\end{tabular}

At the second operation, the group assignment were exchanged. The data are expressed as mean \pm SD or patient number. Group P: combined use of propofol and alfentanil. Group D: use of dexmedetomidine.

These were comparable between the two groups.

Postoperative ISAS was $50.3 \pm 6.2$ in group D and $42.7 \pm 8.7$ in group $\mathrm{P}$ with significant difference $(\mathrm{P}<0.001)$. Median (interquartile range) values of ISAS were $50(48-55)$ vs. 45.0 (39-49) for group D vs. group P, respectively (Fig. 2), indicating more satisfactory condition in group D. 
Changes of hemodynamic and respiratory variables are presented in Fig. 3. Initial SBPs were not different between the two groups $(130 \pm 15 \mathrm{mmHg}$ for group D vs. $133 \pm 19 \mathrm{mmHg}$ for group $\mathrm{P}, \mathrm{P}=0.603)$. However, SBP was significantly lower

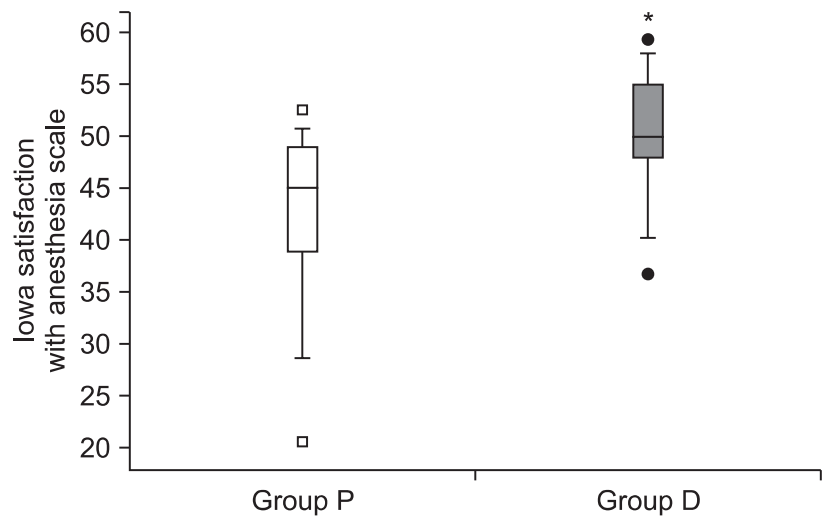

Fig. 2. Box plot of Iowa satisfaction with anesthesia scale of both groups. Group P: combined use of propofol and alfentanil. Group D: use of dexmedetomidine. ${ }^{*} \mathrm{P}<0.05$ compared with group $\mathrm{P}$.
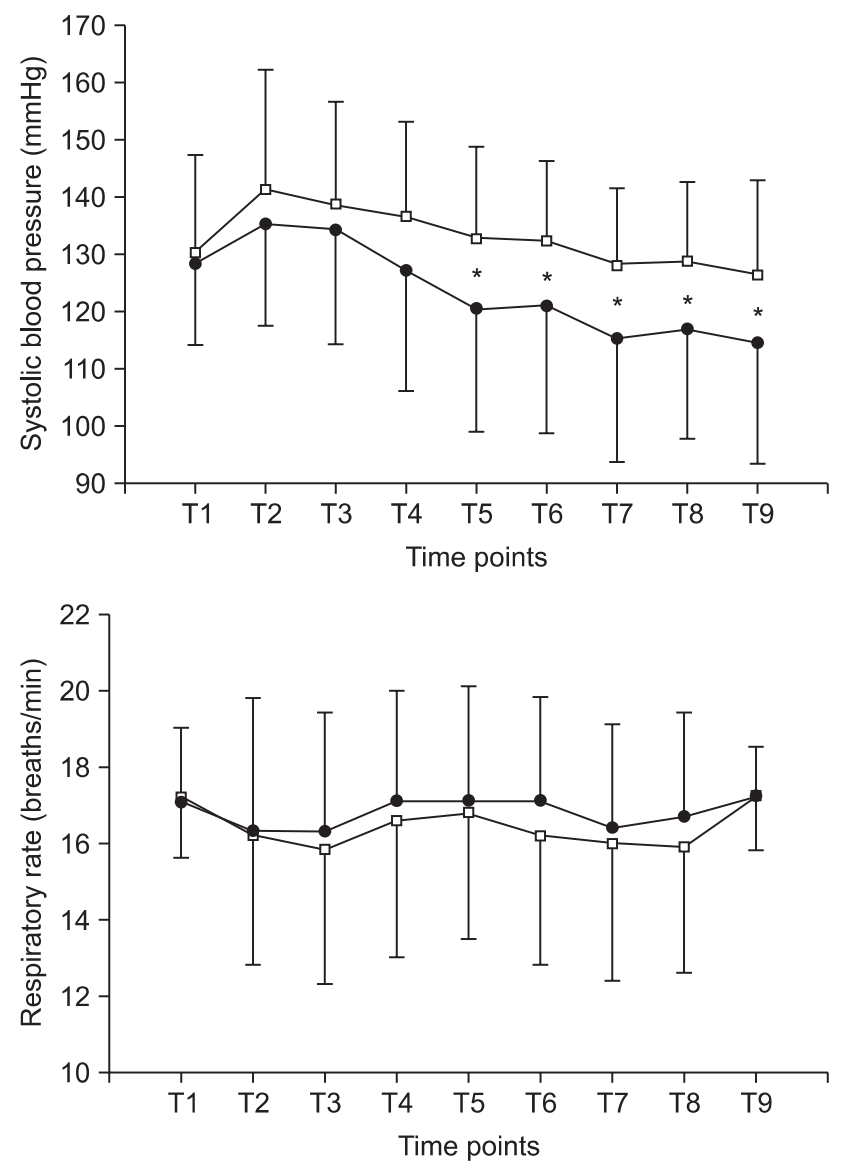

in group $\mathrm{D}(117 \pm 16,117 \pm 17,114 \pm 15,112 \pm 14$, and $107 \pm 15)$ compared with group P $(129 \pm 19,129 \pm 18,127 \pm 18,126 \pm 15$, and $129 \pm 18)$ from the beginning of the operation $(\mathrm{P}<0.05)$. $\mathrm{HR}, \mathrm{RR}$ and $\mathrm{SpO}_{2}$ were comparable between two groups.

There were 8 cases $(25.8 \%)$ of hypertension in group $\mathrm{P}$, and 1 case $(3.2 \%)$ in group $\mathrm{D}(\mathrm{P}<0.05)$. In contrast, 1 case $(3.2 \%)$ of hypotension and 1 case (3.2\%) of bradycardia occurred in group D. In group $\mathrm{D}$, hypotension in one patient occurred only once during the entire period and the lowest SBP was $85 \mathrm{mmHg}$. The lowest HR in a patient of group D who showed bradycardia was 40 beats/min. No episodes of respiratory depression or oxygen desaturation were observed in either group.

\section{Discussion}

In this study, our results suggest that dexmedetomidine is an effective and safe drug for MAC in outpatients undergoing cataract surgery. Dexmedetomidine has been used in short or long term sedation in the intensive care unit, sedation for various procedures, or as a supplementary drug during
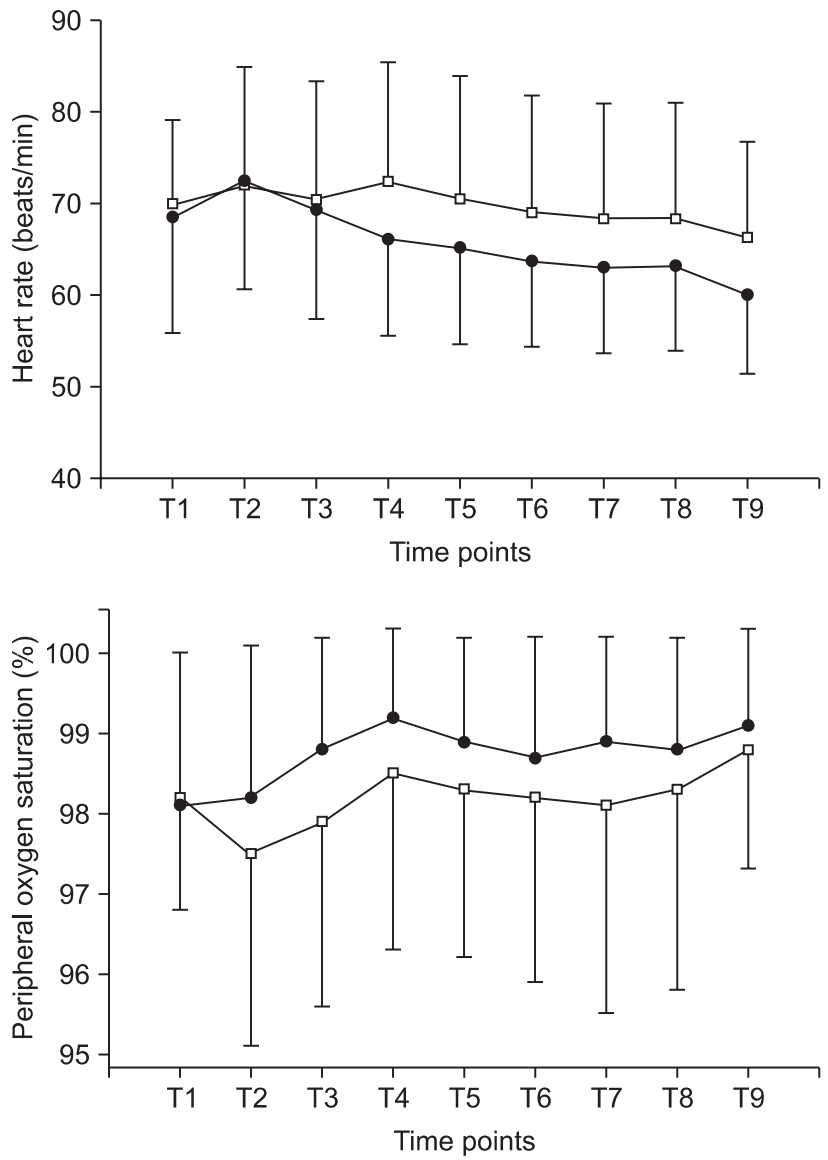

Fig. 3. Changes of hemodynamic and respiratory variables. Group P: combined use of propofol and alfentanil, Group D: use of dexmedetomidine. T1: baseline, T2: anesthesia start, T3 and T4: 5 and 10 min after anesthesia, T5: operation start, T6, T7, and T8: 5, 10, and 15 min after operation, T9: postoperation. Black circle: group D, white square: group P. *P $<0.05$ in group P vs. group D. 
general anesthesia. Previous studies have reported that dexmedetomidine can also be used effectively in cataract surgery.

Ayoglu et al. [19] demonstrated that intraocular pressure was decreased and satisfactory sedation and analgesia were achieved by a sole loading infusion of $1 \mu \mathrm{g} / \mathrm{kg}$ dexmedetomidine for 10 min preoperatively. Apan et al. [20] also reported that dexmedetomidine made the intraoperative HR more stable and postoperative pain less severe compared with midazolam, thus it was appropriate for sedation and analgesia during MAC in cataract surgery. On the contrary, Alhashemi [21] reported that dexmedetomidine was not suitable compared with midazolam because it accompanied cardiovascular depression and delayed the discharge from the recovery room. In that study, dexmedetomidine was administered with $1 \mu \mathrm{g} / \mathrm{kg}$ over $10 \mathrm{~min}$ and infused at $0.1-0.7 \mu \mathrm{g} / \mathrm{kg} / \mathrm{h}$ during the surgery. It was thought that relatively high loading dose and infusion rate might have caused cardiovascular suppression.

Use of loading dose of dexmedetomidine is still controversial because of the development of cardiovascular depression. Dexmedetomidine at a rate of $0.25-2 \mu \mathrm{g} / \mathrm{kg}$ resulted in a reduction of arterial pressure and cardiac output, although large doses ( 1 or $2 \mu \mathrm{g} / \mathrm{kg}$ ) of dexmedetomidine produced the initial increase of arterial pressure temporarily, presumably due to peripheral vasoconstriction [22]. In this current study, loading dose of dexmedetomidine was omitted. There were results reporting that appropriate sedation and stable hemodynamics were achieved in the absence of loading dose of dexmedetomidine [23], and the incidence of hypotension was decreased in ICU sedation without the loading dose [24].

Considering that cataract surgery is less invasive and takes a short time, loading dose of dexmedetomidine is thought to cause postoperative hypotension more frequently, thus only continuous infusion was initiated and adjusted depending on the Ramsay sedation scale of patients during the operation. Therefore, severe hypotension did not occur intra- and postoperatively, and there was no profound sedation delaying discharge. On the other hand, intraoperative arterial pressure was kept stable without additional requirement of antihypertensive drug.

Additionally, the subjective satisfaction score by ISAS in group D was higher than that of group P. Dexmedetomidine enables the patient to convert easily between sedative and cooperative state; therefore, cooperative sedation makes patients more comfortable during the cataract surgery. When propofol and alfentanil were used, immediate interactions with the surgeon did not go smoothly due to the patients' sedated state; however inadequate sedation would lead to patient discomfort. In this study, we did not check the surgeon's satisfaction. However, dexmedetomidine's property of cooperative sedation may enable the surgeon to perform surgery more efficiently.

In this study, one could raise doubt about the doses of drugs between two groups. Dexmedetomidine can be administered as a continuous infusion of $0.2-0.7 \mu \mathrm{g} / \mathrm{kg} / \mathrm{h}$ following $1 \mu \mathrm{g} / \mathrm{kg}$ loading infusion over $10 \mathrm{~min}$ [8]. It has been suggested that $1-2$ $\mathrm{mg} / \mathrm{kg} / \mathrm{h}$ of propofol infusion may achieve a satisfactory level for conscious sedation [25], and propofol infusion of 25-50 $\mu \mathrm{g}$ / $\mathrm{kg} / \mathrm{min}$ in combination with alfentanil infusion of $0.2-0.4 \mu \mathrm{g} /$ $\mathrm{kg} / \mathrm{min}$ was recommended for sedation and analgesia during MAC in healthy outpatients undergoing breast biopsy [26]. The drug infusion rates of previous studies are comparable with those in this study, and the drug infusion rate was titrated to the Ramsay sedation score of 3 . Therefore, it seems not to influence the outcomes of this study.

Dexmedetomidine is unique in that it does not cause respiratory depression because its mechanism is not mediated by the $\gamma$-aminobutyric acid system [8]. It has been proved in critically ill patients given dexmedetomidine during surgery as well as those given the drug for short term $[27,28]$. In addition to this singular property of dexmedetomidine, less use of rescue sedative or analgesic drugs might also contribute to less respiratory depression. In the present study, total anesthesia time was around $30 \mathrm{~min}$. It was not a very long period; however, intraoperative $\mathrm{RR}$ and $\mathrm{SpO}_{2}$ of group $\mathrm{D}$ were somewhat superior to group P. Most of the patients were outpatients and elderly, thus we suggest that dexmedetomidine has more advantages over other commonly used sedatives. In addition to previous affirmative results $[20,29]$ such as sedative plus analgesic properties, stable hemodynamic state, and low IOP, dexmedetomidine should be recommended for MAC in cataract surgery.

Combined use of benzodiazepine and opioid may be associated with a potential risk for developing delirium, whereas, dexmedetomidine can minimize the occurrence of delirium in critically ill or elderly patients. The incidence of delirium was $50 \%$ in patients receiving propofol or midazolam for postoperative sedation; however, only $3 \%$ of patients receiving dexmedetomidine presented postoperative delirium [30]. This is yet another advantage of dexmedetomidine as a sedative in patients with high risks of delirium.

In conclusion, we showed that dexmedetomidine seems to be an acceptable agent for MAC in outpatients undergoing cataract surgery. Compared with propofol/alfentanil, dexmedetomidine reduced arterial pressure during the period of operation. Satisfaction scores were also in favor of the patients treated with dexmedetomidine. 


\section{References}

1. Rosenfeld SI, Litinsky SM, Snyder DA, Plosker H, Astrove AW, Schiffman J. Effectiveness of monitored anesthesia care in cataract surgery. Ophthalmology 1999; 106: 1256-60.

2. Cok OY, Ertan A, Bahadir M. Comparison of midazolam sedation with or without fentanyl in cataract surgery. Acta Anaesthesiol Belg 2008; 59: 27-32.

3. Celiker V, Basgul E, Sahin A, Uzun S, Bahadir B, Aypar U. Comparison of midazolam, propofol and fentanyl combinations for sedation and hemodynamic parameters in cataract extraction. Saudi Med J 2007; 28: 1198-203.

4. Frey K, Sukhani R, Pawlowski J, Pappas AL, Mikat-Stevens M, Slogoff S. Propofol versus propofol-ketamine sedation for retrobulbar nerve block: comparison of sedation quality, intraocular pressure changes, and recovery profiles. Anesth Analg 1999; 89: 317-21.

5. Weinbroum AA, Szold O, Ogorek D, Flaishon R. The midazolaminduced paradox phenomenon is reversible by flumazenil. Epidemiology, patient characteristics and review of the literature. Eur J Anaesthesiol 2001; 18: 789-97.

6. Janzen PR, Christys A, Vucevic M. Patient-controlled sedation using propofol in elderly patients in day-case cataract surgery. $\mathrm{Br} \mathrm{J}$ Anaesth 1999; 82: 635-6.

7. Bhananker SM, Posner KL, Cheney FW, Caplan RA, Lee LA, Domino KB. Injury and liability associated with monitored anesthesia care: a closed claims analysis. Anesthesiology 2006; 104: 228-34.

8. Gerlach AT, Dasta JF. Dexmedetomidine: an updated review. Ann Pharmacother 2007; 41: 245-52.

9. Hall JE, Uhrich TD, Barney JA, Arain SR, Ebert TJ. Sedative, amnestic, and analgesic properties of small-dose dexmedetomidine infusions. Anesth Analg 2000; 90: 699-705.

10. Bergese SD, Khabiri B, Roberts WD, Howie MB, McSweeney TD, Gerhardt MA. Dexmedetomidine for conscious sedation in difficult awake fiberoptic intubation cases. J Clin Anesth 2007; 19: 141-4.

11. Siddappa R, Riggins J, Kariyanna S, Calkins P, Rotta AT. High-dose dexmedetomidine sedation for pediatric MRI. Paediatr Anaesth 2011; 21: 153-8.

12. Tan JA, Ho KM. Use of dexmedetomidine as a sedative and analgesic agent in critically ill adult patients: a meta-analysis. Intensive Care Med 2010; 36: 926-39.

13. Muller S, Borowics SM, Fortis EA, Stefani LC, Soares G, Maguilnik I, et al. Clinical efficacy of dexmedetomidine alone is less than propofol for conscious sedation during ERCP. Gastrointest Endosc 2008; 67: 651-9.

14. Kaygusuz K, Gokce G, Gursoy S, Ayan S, Mimaroglu C, Gultekin Y. A comparison of sedation with dexmedetomidine or propofol during shockwave lithotripsy: a randomized controlled trial. Anesth Analg 2008; 106: 114-9.
15. Bekker A, Sturaitis M, Bloom M, Moric M, Golfinos J, Parker E, et al. The effect of dexmedetomidine on perioperative hemodynamics in patients undergoing craniotomy. Anesth Analg 2008; 107: 1340-7.

16. Bulow NM, Barbosa NV, Rocha JB. Opioid consumption in total intravenous anesthesia is reduced with dexmedetomidine: a comparative study with remifentanil in gynecologic videolaparoscopic surgery. J Clin Anesth 2007; 19: 280-5.

17. Ramsay MA, Savege TM, Simpson BR, Goodwin R. Controlled sedation with alphaxalone-alphadolone. Br Med J 1974; 2: 656-9.

18. Dexter F, Aker J, Wright WA. Development of a measure of patient satisfaction with monitored anesthesia care: the Iowa Satisfaction with Anesthesia Scale. Anesthesiology 1997; 87: 865-73.

19. Ayoglu H, Altunkaya H, Ozer Y, Yapakci O, Ozkocak I, Oz O, et al. Dexmedetomidine sedation during cataract surgery under regional anaesthesia. Br J Anaesth 2007; 99: 448.

20. Apan A, Doganci N, Ergan A, Büyükkoçak U. Bispectral indexguided intraoperative sedation with dexmedetomidine and midazolam infusion in outpatient cataract surgery. Minerva Anestesiol 2009; 75: 239-44.

21. Alhashemi JA. Dexmedetomidine vs midazolam for monitored anaesthesia care during cataract surgery. Br J Anaesth 2006; 96: 722-6.

22. Bloor BC, Ward DS, Belleville JP, Maze M. Effects of intravenous dexmedetomidine in humans. II. Hemodynamic changes. Anesthesiology 1992; 77: 1134-42.

23. Ickeringill M, Shehabi Y, Adamson H, Ruettimann U. Dexmedetomidine infusion without loading dose in surgical patients requiring mechanical ventilation: haemodynamic effects and efficacy. Anaesth Intensive Care 2004; 32: 741-5.

24. Gerlach AT, Dasta JF, Steinberg S, Martin LC, Cook CH. A new dosing protocol reduces dexmedetomidine-associated hypotension in critically ill surgical patients. J Crit Care 2009; 24: 568-74.

25. Lundström S, Twycross R, Mihalyo M, Wilcock A. Propofol. J Pain Symptom Manage 2010; 40: 466-70.

26. Avramov MN, White PF. Use of alfentanil and propofol for outpatient monitored anesthesia care: determining the optimal dosing regimen. Anesth Analg 1997; 85: 566-72.

27. Belleville JP, Ward DS, Bloor BC, Maze M. Effects of intravenous dexmedetomidine in humans. I. Sedation, ventilation, and metabolic rate. Anesthesiology 1992; 77: 1125-33.

28. Venn RM, Hell J, Grounds RM. Respiratory effects of dexmedetomidine in the surgical patient requiring intensive care. Crit Care 2000; 4: 302-8.

29. Abdalla MI, Al Mansouri F, Bener A. Dexmedetomidine during local anesthesia. J Anesth 2006; 20: 54-6.

30. Maldonado JR, Wysong A, van der Starre PJ, Block T, Miller C, Reitz BA. Dexmedetomidine and the reduction of postoperative delirium after cardiac surgery. Psychosomatics 2009; 50: 206-17. 
Appendix 1. Ramsay Sedation Scale [17]

1: Patient is anxious and agitated or restless, or both

2: Patient is cooperative, oriented, and tranquil.

3: Patient responds to command only.

4: A brisk response to a light glabella tap or a loud auditory stimulus.

5: A sluggish response to a light glabella tap or a loud auditory stimulus. 6: No response to a light glabella tap or a loud auditory stimulus.
Appendix 2. Iowa Satisfaction with Anesthesia Scale [18]

\section{I threw up or felt like throwing up.*}

I would have the same anesthetic again.

I itched.*

I felt relaxed.

I felt pain.*

I felt safe.

I was too hot or cold.*

I was satisfied with the anesthesia care.

I felt pain during surgery.*

I felt good.

I hurt.*

Each item uses 6 point response scored from 1 to 6 (disagree very much, disagree moderately, disagree slightly, agree slightly, agree moderately, agree very much). *The scores were reversed in negative questions. 